\title{
Praktek Ibu dalam Perawatan Neonatus di Kabupaten Garut, Jawa Barat
}

\author{
Aji Haryanto* Ella Nurlaella Hadi***
}

\begin{abstract}
Abstrak
Angka kematian bayi (AKB) di Kabupaten Garut pada tahun 2005 (54,8 per 1000 kelahiran hidup) merupakan yang tertinggi di provinsi Jawa Barat, akibat kematian neonatus dalam tiga tahun terakhir terus meningkat. Studi yang bertujuan mengetahui determinan praktek ibu dalam perawatan neonatus, dilakukan dengan analisis lanjut data Survei Dasar Kesehatan Neonatus Esensial di Kabupaten Garut tahun 2007. Analisis dilakukan dengan menggunakan metoda regresi logistik ganda. Hasil studi menunjukkan, dari 577 ibu bayi 1 - 11 bulan yang menjadi sampel penelitian, sekitas $51,5 \%$ ibu melakukan praktek perawatan neonatus kurang baik. Faktor yang paling dominan berhubungan dengan praktek perawatan neonatus adalah pengetahuan ibu setelah dikontrol oleh dukungan keluarga, pendidikan ibu, pekerjaan ibu dan penyuluhan oleh tenaga kesehatan. Ibu yang berpengetahuan baik melakukan praktek perawatan neonatus baik 2,2 kali lebih besar daripada ibu yang dengan pengetahuan kurang baik. Disarankan agar Bidan di Desa (BdD) mengubah cara pemberian informasi kepada ibu dan keluarganya dengan metode diskusi dan menggunakan gambar serta buku Kesehatan Ibu dan Anak (KIA), sehingga ibu lebih mudah memahami dan menerapkan kepada bayinya.
\end{abstract}

Kata kunci : Perawatan neonatus, kesehatan neonatus, AKB

\begin{abstract}
Infant Mortality Rate (IMR) in 2005 at Garut District (54.8/1000 live births), is the highest in West Java Province, due to ever increasing neonatus mortality rates in the last three year. The purpose of this study was to investigate the determinant of mother's practice in neonatus care at Garut District, conducted by advance analysis of Baseline Survey of Essential Neonatus Health Services at Garut District data in 2007. The data was analyzed using chi square test and multiple logistic regression. The result of this study showed that out of 577 baby mothers who had $1-11$ months as the sample of this research, $51.5 \%$ had unfavorable practice in neonatus care. The most dominant factor related to practice in neonatus care was knowledge of mother after adjusting by family support, mother's education, mother's occupation and counseling by health provider. Mothers who have good knowledge in neonatus care practice had chance 2.2 times higher compared to mothers who had unfavorable knowledge to implement good practice. Based on the result of this study, it is suggested that the Village Midwives should change the way in giving of information to mothers and her families by using more discussion method and utilizing picture, and also utilizing Maternal and Child Health book, so that it would be easier for the mothers to understand and to apply good practices to their babies.
\end{abstract}

Key words : Neonatus care, neonatus health, ilnfant mortality rate 
Angka kematian bayi (AKB) di Indonesia menunjukkan kecenderungan yang menurun. Survei Demografi dan Kesehatan Indonesia (SDKI) tahun 1997 menunjukkan AKB 46 per 1000 kelahiran hidup (KH), tahun 2002 (35 per $1000 \mathrm{KH}$ ) dan tahun 2007 (34 per $1000 \mathrm{KH}){ }^{1}$ Hasil Survei Kesehatan Rumah Tangga (SKRT) tahun 2001, menemukan angka kematian neonatus (AKN) 25 per $1000 \mathrm{KH}$, SDKI tahun 2002-2003 serta 2007 masing-masing menunjukkan 20 per $1000 \mathrm{KH}$ juga memperlihatkan kecenderungan yang menurun. ${ }^{2}$ Meskipun belum mencapai target 15 per $1000 \mathrm{KH}$.

Kematian bayi mengambil proporsi terbesar kematian balita dan sebagian besar terjadi pada periode neonatus. AKN berkontribusi paling tinggi pada $\mathrm{AKB}$ yang mencapai $75 \% .{ }^{3}$ Menurut SKRT 2001, 79,4\% kematian neonatus terjadi sampai usia 7 hari dan $20,6 \%$ terjadi pada usia 8-28 hari. ${ }^{4}$ Kematian yang terjadi pada usia neonatus menunjukkan status kesehatan bayi baru lahir (BBL) akses dan kualitas pelayanan kesehatan bayi pada masa periode segera setelah lahir yang masih rendah, serta perilaku ibu dan keluarga yang masih buruk. 5

Meskipun secara nasional telah terjadi penurunan $\mathrm{AKB}$, tetapi variasi antar provinsi masih sangat besar. Menurut SDKI 2002-2003, AKB di Provinsi Jawa Barat 44 per $1000 \mathrm{KH}$ dan tahun 2004 (43,4 per $1000 \mathrm{KH})$ menduduki peringkat teratas di antara semua provinsi di pulau Jawa.1,6 AKB di Kabupaten Garut pada tahun 2004 (55,9 per $1000 \mathrm{KH})$ dan tahun 2005 (54,8 per $1000 \mathrm{KH})$, masih jauh di atas rata-rata AKB Provinsi Jawa Barat dan merupakan yang paling tinggi di antara semua kabupaten/kota di Provinsi Jawa Barat. ${ }^{6}$ Status kesehatan neonatus di Kabupaten Garut yang rendah tersebut dapat dilihat dari kasus kematian neonatus dalam tiga tahun terakhir yang masih tinggi. Pada tahun 2003 dan 2005 masing-masing 272 dan 297 tergolong tinggi. Hal ini mengindikasikan masih banyak ibu yang belum melakukan perawatan BBL secara memadai. Untuk mengatasi masalah tersebut, pada tahun 2007, di Kabupaten Garut telah dilakukan Survei Data Dasar Kesehatan Neonatus Esensial.

Banyak faktor yang mempengaruhi perilaku manusia, antara lain adalah pengetahuan, pendidikan, pekerjaan dan kepercayaan yang ada di masyarakat. ${ }^{6}$ Menurut Kar, ${ }^{7}$ dukungan keluarga dan ketersediaan informasi juga mempengaruhi perilaku seseorang. Oleh sebab itu, Data Survei Kesehatan Neonatus Esensial di Kabupaten Garut tersebut perlu dianalisis lebih lanjut. Tujuan penelitian ini adalah mengetahui determinan praktek ibu dalam perawatan BBL di Kabupaten Garut guna dijadikan acuan upaya percepatan penurunan AKB dan AKN di Kabupatan
Garut.

\section{Metode}

Penelitian menggunakan sumber data sekunder Survei Data Dasar Kesehatan Neonatus Esensial di Kabupaten Garut Provinsi Jawa Barat Tahun 2007. Studi yang dilakukan oleh Pusat Penelitian Kesehatan dan Pusat Promosi Kesehatan FKM UI tersebut menggunakan desain potong lintang. Populasi penelitian ini adalah seluruh ibu yang memiliki bayi 1-11 bulan, untuk menjawab pertanyaan pengalaman penanganan bayi neonatal sampai usia 26 hari. Penelitian dilakukan di 10 kecamatan yang meliputi Pameungpeuk, Cisompet, Cikajang, Banjarwangi, Limbangan, Selaawi, Malangbong, Bungbulang, Bayongbong, dan Sukamulya, Kabupaten Garut. Sampel dihitung dengan menggunakan uji hipotesis dua proporsi dan diambil dengan metode klaster probability proportionate to size. Jumlah sampel yang memenuhi kriteria adalah $577 \mathrm{ibu}$. Analisis data dilakukan secara bertahap meliputi analisis univariat, analisis bivariat dengan uji Chi square serta analisis multivariat menggunakan regresi logistik ganda.

\section{Hasil \\ Gambaran Praktek Perawatan Neonatus}

Praktek perawatan neonatus yang dilakukan ibu mencakup perawatan tali pusat, pemberian ASI dan menjaga kehangatan tubuh bayi untuk mencegah hipotermi. Hasil penelitian ini menemukan sekitar separuh $(51,5 \%)$ ibu mempraktikkan perawatan neonatus secara kurang baik. Masih banyak ibu yang tidak melakukan perawatan tali pusat seperti yang dianjurkan oleh Depkes/WHO, tidak menutup dan memberikan apapun pada tali pusat. Lebih dari separuh ibu (59,3\%) masih memberikan betadine/povidon yodium/alkohol dan $24,1 \%$ ibu masih menutup tali pusat dengan kassa. Sebagian besar ibu $(76,6 \%)$ memberikan kolostrum kepada bayinya dan sebanyak $81,3 \%$ ibu hanya memberikan ASI saja dalam 3 hari pertama kelahiran, tetapi hanya $22,7 \%$ ibu yang tidak pernah memberikan makanan/minuman lain selain ASI. Hampir semua ibu (96\%) masih memberikan ASI kepada bayinya ketika penelitian dilakukan. Praktek ibu dalam menjaga kehangatan tubuh bayi masih buruk karena sekitar 61,7\% hanya menyelimuti tubuh bayi dengan selimut. Namun, tindakan yang lain seperti menunda memandikan pertama kali, meletakkan bayi di dada, kontak langsung dengan kulit ibu, memakaikan kaus kaki, sarung tangan dan topi tidak dilakukan.

Pada tabel 1 terlihat, sebagian besar ibu berpendidikan rendah yaitu SLTP ke bawah dan tidak bekerja. Sekitar separuh ibu berpengetahuan baik tentang perawatan neonatus dan menilai penyuluhan 
Tabel 1. Distribusi Ibu Menurut Praktek Perawatan Neonatus dan Determinannya di Kabupaten Garut, Jawa Barat Tahun 2007

\begin{tabular}{llll}
\hline Variabel & Kategori & n & $\%$ \\
\hline Praktek Perawatan Neonatus & Baik & 280 & 48,5 \\
Pendidikan Ibu & Kurang baik & 297 & 51,5 \\
& Tamat SLTA+ & 76 & 13,3 \\
& Tamat SLTP & 435 & 76,2 \\
Pekerjaan Ibu & Tak tamat SD & 60 & 10,5 \\
& Tidak bekerja & 510 & 89,8 \\
Pengetahuan tentang Perawatan Neonatus & Bekerja & 58 & 10,2 \\
& Baik & 304 & 52,7 \\
Penyuluhan oleh Nakes & Kurang baik & 273 & 47,3 \\
& Baik & 130 & 51,6 \\
Dukungan Keluarga & Kurang baik & 122 & 48,4 \\
Kepercayaan di Lingkungan & Cukup & 238 & 51,6 \\
yang Merugikan Kesehatan & Kurang & 339 & 48,4 \\
& Tidak ada & 18 & 3,1 \\
& Ada & 559 & 96,9 \\
\hline
\end{tabular}

yang diberikan oleh tenaga kesehatan sudah baik. Lebih dari separuh ibu mengatakan dukungan yang diberikan keluarga dalam perawatan neonatus kurang dan hampir semua ibu $(96,9 \%)$ mengatakan di lingkungan tempat tinggalnya tidak ada kepercayaan yang merugikan kesehatan bayi (Lihat Tabel $1)$.

\section{Seleksi Variabel Kandidat ke Model Multivariat}

Berdasarkan hasil uji Chi Square antara 6 variabel yang diduga berhubungan dengan praktek ibu dalam perawatan neonatus didapatkan 5 variabel yang memenuhi kriteria kandidat model multivariat yaitu nilai p uji statistik $\leq 0,25$ meliputi pendidikan ibu, pekerjaan ibu, pengetahuan perawatan neonatus, penyuluhan oleh tenaga kesehatan dan dukungan keluarga (Lihat Tabel 2).

\section{Determinan Praktek Perawatan Neonatus}

Analisis multivariat dilakukan dengan memasukkan semua variabel kandidat dan diikuti dengan pengeluaran satu per satu variabel yang memiliki nilai $p>0,05$ dengan memperhatikan selisih perubahan OR. Pada tabel 3 terlihat, terdapat 3 variabel yang memiliki nilai $\mathrm{p}>0,05$ yaitu pendidikan ibu, pekerjaan ibu dan penyuluhan oleh tenaga kesehatan dan karena pendidikan ibu merupakan variabel yang memiliki nilai $\mathrm{p}$ terbesar maka pendidikan ibu dikeluarkan pertama kali dari model. Pengeluaran variabel pendidikan ibu dari model menyebabkan perubahan nilai OR dari pekerjaan ibu $>10 \%$. Oleh sebab itu, variabel pendidikan ibu tidak bisa dikeluarkan dari model karena merupakan confounding pada hubungan antara pekerjaan ibu dengan praktek ibu dalam perawatan
Tabel 2. Seleksi Kandidat Model Multivariat

\begin{tabular}{lll}
\hline Variabel & Nilai p & Keterangan \\
\hline Pendidikan ibu & 0,019 & Kandidat \\
Pekerjaan ibu & 0,223 & Kandidat \\
Pengetahuan tentang perawatan neonatus & 0,0005 & Kandidat \\
Penyuluhan oleh Nakes & 0,081 & Kandidat \\
Dukungan Keluarga & 0,0005 & Kandidat \\
Kepercayaan yang merugikan kesehatan & 0,404 & Bukan kandidat
\end{tabular}

neonatus.

Langkah selanjutnya adalah mengeluarkan variabel penyuluhan oleh tenaga kesehatan dari model dan hasilnya adalah terjadinya perubahan nilai OR $>10 \%$ dari variabel pengetahuan dan dukungan keluarga. Oleh sebab itu, variabel penyuluhan oleh tenaga kesehatan tidak dapat dikeluarkan dari model karena merupakan confounding pada hubungan antara pengetahuan ibu dengan praktek ibu dalam perawatan neonatus dan pada hubungan antara dukungan keluarga dengan praktek ibu dalam perawatan neonatus.

Diduga adanya interaksi antara variabel pengetahuan ibu dengan penyuluhan oleh tenaga kesehatan, pengetahuan ibu dengan pendidikan ibu dan antara pengetahuan ibu dengan pekerjaan ibu. Oleh karena itu, ketiga variabel interaksi tersebut dimasukkan ke dalam model. Hasil uji Omnibus menunjukkan tidak adanya interaksi antara pengetahuan ibu dengan penyuluhan oleh tenaga kesehatan $(\mathrm{p}=0,950)$, pengetahuan ibu dengan pendidikan ibu $(\mathrm{p}=0,137)$ dan antara pengetahuan ibu dengan pekerjaan ibu $(p=0,123)$, sehingga model akhir kembali ke model seperti yang terlihat pada Tabel 3 . Pengetahuan ibu merupakan faktor yang paling dominan berhubungan dengan praktek ibu dalam perawatan 
Tabel 3. Model Akhir Multivariat

\begin{tabular}{lccccc}
\hline Variabel & Koef & SE & Nilai $\mathbf{p}$ & OR & $\mathbf{9 5 \%}$ CI \\
\hline $\begin{array}{l}\text { Pendidikan ibu } \\
\quad \text { Tamat SLTA+ }\end{array}$ & 0,411 & 0,609 & 0,499 & 1,5 & $0,5-5,0$ \\
$\quad$ Tamat SLTP & 0,803 & 0,541 & 0,138 & 2,2 & $0,8-6,5$ \\
$\quad$ Tamat SD & & & 0,212 & & \\
Pekerjaan ibu & 0,442 & 0,485 & 0,362 & 1,6 & $0,6-4,0$ \\
Pengetahuan & 0,768 & 0,281 & 0,006 & 2,2 & $1,2-3,7$ \\
Penyuluhan Nakes & 0,275 & 0,271 & 0,311 & 1,3 & $0,8-2,2$ \\
Dukungan Keluarga & 0,543 & 0,276 & 0,049 & 1,7 & $1,0-3,0$ \\
\hline
\end{tabular}

neonatus. Ibu yang pengetahuannya baik, berpeluang 2,2 kali melakukan praktek perawatan neonatus baik dibanding ibu yang pengetahuannya kurang baik setelah dikontrol oleh dukungan keluarga, pendidikan ibu, pekerjaan ibu dan penyuluhan oleh tenaga kesehatan (Lihat Tabel $3)$.

\section{Pembahasan}

Pengetahuan ibu merupakan faktor yang paling dominan berhubungan dengan praktek perawatan neonatus setelah dikontrol penyuluhan oleh tenaga kesehatan, dukungan keluarga, pendidikan ibu dan pekerjaan ibu. Hubungan tersebut menunjukkan bahwa pengetahuan merupakan faktor predisposisi bagi ibu dalam merawat bayinya. ${ }^{8}$ Ibu dengan pengetahuan yang baik akan diikuti dengan praktek yang baik pula dalam memberikan perawatan kepada bayinya. Hal ini juga dibuktikan oleh Fauzi dalam penelitiannya, ibu yang memiliki pengetahuan tinggi berpeluang hampir 20 kali untuk memberikan ASI eksklusif dibanding ibu yang pengetahuannya rendah. ${ }^{9}$ Pada penelitian ini baru separuh ibu-ibu di Kabupaten Garut yang pengetahuan dan berpraktek yang baik dalam perawatan neonatus. Menurut WHO, pengetahuan ibu dapat diperoleh dari pengalaman sendiri maupun dari pengalaman orang lain, baik dari keluarga yang turut membantu ibu merawat bayinya, teman maupun dari tenaga kesehatan yang melakukan pemeriksaan kehamilan dan menolong persalinan. ${ }^{7}$ Atas dasar tersebut maka tenaga kesehatan harus memberikan informasi secara terus-menerus kepada ibu sehingga pengetahuan dan praktek ibu dalam perawatan neonatus sesuai dengan standar kesehatan.

Penelitian ini juga menemukan hubungan yang bermakna antara dukungan keluarga dan praktek ibu dalam perawatan neonatus setelah dikontrol oleh pengetahuan ibu, penyuluhan oleh tenaga kesehatan, pendidikan ibu dan pekerjaan ibu. Ibu yang menilai dukungan keluarga cukup, berpeluang 1,7 kali untuk melakukan praktek baik dalam perawatan neonatus daripada ibu yang menilai dukungan keluarga kurang. Seorang ibu yang baru sa- ja melahirkan (khususnya pada kelahiran anak pertama) sedang berada pada proses penyesuaian peran menjadi orang tua yang secara sadar atau tidak membutuhkan dukungan dari suami dan keluarga dekat lainnya. 8,10 Menurut Mercer dan Crawford, jaringan kekerabatan dapat menjadi dukungan sekaligus sumber masalah, karena nasihat yang diterima ibu bisa saja bertentangan dengan prinsip kesehatan sehingga mempengaruhi praktek ibu dalam merawat bayinya. ${ }^{10}$ Penelitian Wijayanti di Lampung dan Nurpelita di Siak menunjukkan hasil yang sama bahwa ada hubungan antara dukungan keluarga dengan praktek pemberian ASI eksklusif..11,12 Oleh sebab itu, keluarga harus menjadi salah satu sasaran tenaga kesehatan dalam memberikan informasi tentang perawatan neonatus, sehingga ibu dapat melakukan perawatan yang adekuat.

Penyuluhan oleh tenaga kesehatan terbukti tidak berhubungan dengan praktek ibu dalam perawatan neonatus. Namun, penyuluhan oleh tenaga kesehatan merupakan confounding pada hubungan antara pengetahuan ibu dengan praktek ibu pada hubungan antara dukungan keluarga dengan praktek ibu dalam perawatan neonatus. Artinya, penyuluhan oleh tenaga kesehatan mempengaruhi pengetahuan ibu, dukungan keluarga dan juga mempengaruhi praktek ibu dalam perawatan neonatus. Hasil penelitian ini menunjukkan praktek ibu dalam perawatan tali pusat dan menjaga kehangatan tubuh bayi masih kurang baik.

Hal ini kemungkinan disebabkan oleh tenaga kesehatan kurang memberikan informasi tentang kedua hal tersebut atau karena cara pemberian informasi yang kurang menarik, sehingga informasi tidak dapat diserap dengan baik oleh ibu dan anggota keluarga. Sebagai akibatnya, keluarga kurang bisa memberikan dukungan kepada ibu, yang pada akhirnya ibu tidak bisa mempraktekkan kedua hal tersebut. Untuk mengatasi hal tersebut, penyuluhan oleh tenaga kesehatan sejogyanya sesuai dengan tingkat pendidikan ibu-ibu dan keluarganya, misalnya harus disertai dengan diskusi, demonstrasi dan menggunakan gambar, lembar balik serta buku KIA sehingga informasi akan lebih mudah diserap oleh ibu maupun 
keluarganya. Selain itu, penyuluhan tidak selalu harus dilakukan di rumah ibu maupun di fasilitas pelayanan kesehatan tetapi dapat dilakukan di kelompok yang ada di masyarakat misalnya kelompok pengajian. Agar dapat melakukan hal tersebut, keterampilan bidan di desa (BdD) dalam komunikasi, edukasi dan informasi (KIE) perlu ditingkatkan, disamping perlunya menyediakan sarana transportasi sehingga pelayanan kesehatan, termasuk pemberian informasi di daerah sulit dapat dilakukan.

Kepercayaan di lingkungan ibu yang dapat merugikan kesehatan bayi terbukti tidak berhubungan dengan praktek ibu dalam perawatan neonatus. Temuan penelitian ini bertentangan dengan teori WHO yang mengatakan kepercayaan akan mempengaruhi perilaku seseorang. ${ }^{7}$ Hal ini karena hampir semua ibu menyatakan tidak ada kepercayaan di masyarakat pada 10 kecamatan daerah penelitian yang merugikan kesehatan neonatus, sehingga tentu saja tidak mempengaruhi praktek ibu dalam perawatan neonatus.

Penelitian ini juga tidak menemukan hubungan antara pendidikan ibu dengan praktek ibu dalam perawatan neonatus. Hasil penelitian ini bertentangan dengan pendapat Kar, ${ }^{7}$ Soetjiningsih \& Suwendar, ${ }^{13}$ serta Unika Atmajaya, ${ }^{14}$ yang menemukan semakin tinggi tingkat pendidikan ibu semakin mudah ibu menerima informasi yang berkaitan dengan pola pengasuhan anak. Perbedaan ini kemungkinan karena pendidikan ibu kurang bervariasi karena pada umumnya rendah.

Penelitian ini juga membuktikan bahwa pendidikan ibu merupakan counfonding pada hubungan antara pekerjaan ibu dengan praktek ibu dalam perawatan neonatus. Artinya, pendidikan ibu mempengaruhi pekerjaan ibu sekaligus mempengaruhi praktek ibu dalam perawatan neonatus. Tingkat pendidikan ibu pada umumnya rendah, sehingga tidak banyak kesempatan yang dimiliki ibu untuk memasuki dunia kerja yang dapat meningkatkan wawasan dan pengetahuannya tentang kesehatan khususnya tentang perawatan neonatus.

Pekerjaan ibu terbukti tidak berhubungan dengan praktek ibu dalam perawatan neonatus, karena hampir semua ibu tidak bekerja, padahal hasil penelitian Unika Atmajaya, ${ }^{14}$ membuktikan bahwa ibu yang bekerja semakin baik pengetahuan dan pola pemberian ASI-nya karena ibu bisa berinteraksi dengan orang-orang di lingkungan kerjanya yang dapat meningkatkan pengetahuan dan akhirnya dapat mempraktekkan pengetahuannya tersebut. Namun demikian, dalam penelitian ini hampir semua ibu tidak bekerja, sehingga pergaulannya kemungkinan juga hanya dengan ibu-ibu yang pengetahuan dan prakteknya dalam perawatan neonatus sama-sama rendah.

\section{Kesimpulan}

Sekitar separuh ibu $(51,5 \%)$ di Kabupaten Garut melakukan praktek perawatan neonatus kurang baik dan faktor yang berhubungan dengannya adalah pengetahuan ibu dan dukungan keluarga, setelah dikontrol oleh pekerjaan ibu, pendidikan ibu dan penyuluhan oleh tenaga kesehatan. Ibu yang pengetahuannya baik akan melakukan praktek perawatan neonatus 2,2 kali lebih baik dibanding ibu yang pengetahuannya kurang baik.

\section{Saran}

Dinas Kesehatan Kabupaten Garut perlu memberikan pelatihan KIE, menambah pos persalinan desa dan sarana transportasi bagi Bidan di Desa (BdD) agar dapat menjangkau wilayah terpencil. BdD perlu mengubah cara penyampaian informasi misalnya dengan menggunakan lembar balik dan buku KIA yang diberikan secara bertahap dan berulang-ulang sehingga ibu dan keluarga lebih mudah memahami dan menyerap inforamasi yang pada akhirnya akan mampu mempraktekkan perawatan neonatus yang adekuat.

\section{Daftar Pustaka}

1. Biro Pusat Statistik (BPS). Survei demografi dan kesehatan Indonesia 2002-2003. Jakarta: BPS; 2003.

2. Biro Pusat Statistik (BPS). Survei demografi dan kesehatan Indonesia 2007-2008. Jakarta: BPS; 2007.

3. Kosim SM. Perawatan neonatus esensial dan nutrisi tumbuh kembang otak [Internet]. Makalah Seminar 2008 [diakses tanggal 14 Juli 2008]. Diunduh dari: http://www.bkkbn.go. id.

4. Djaja S \& Soemantri S. Penyakit penyebab kematian bayi baru lahir (neonatal) dan sistem pelayanan kesehatan yang berkaitan di Indonesia SKRT 2001. Buletin Penelitian Kesehatan Badan Penelitian dan Pengembangan Kesehatan, Depkes RI. 2003; 3 (3).

5. Bappenas. Laporan perkembangan pencapaian Millennium Development Goals Indonesia 2007. [diakses tanggal 10 Desember 2008]. Diunduh dari: http://www.bappenas.go. id/.

6. WHO. Education for health: a manual on health education in primary health care. Geneva: WHO; 1988.

7. Kar SBA. Psychological of health behaviour. Health Values, Achieving high Level Wellness. 1983; 7 (2).

8. Green LW \& Kreuter MW. Health program planning an educational and ecological approach. Fourth Edition. New York; 2005.

9. Fauzi A. Determinan perilaku ibu dalam pemberian ASI eksklusif di wilayah kerja puskesmas Meurah Dua Kabupaten Pidie Jaya, Tahun 2008 [tesis]. Depok: FKMUI; 2008.

10. Bobak. Buku ajar keperawatan maternitas. $4^{\text {th }}$ Edition. Jakarta: Buku Kedokteran EGC; 1998.

11. Wijayanti TY. Hubungan antara karakteristik pengetahuan ibu 
tentang ASI eksklusif dan dukungan eksternal dengan praktek pemberian ASI pada bayi di kelurahan Yosomulyo Kota Metro, Provinsi Lampung tahun 2005 [skripsi]. Depok: FKMUI; 2005.

12. Nurpelita. Faktor-faktor yang berhubungan dengan pemberian ASI eksklusif di wilayah kerja puskesmas Buatan II Siak Tahun 2007 [tesis].
Depok: FKMUI; 2007.

13. Soetjiningsih \& Suwendra. ASI penjaga pelindung bayi. Denpasar: Tim Penyuluhan IDAI Bali, BKPP-ASI Bali, Perinasia Bali; 1990.

14. Unika Atmajaya. Praktek pemberian ASI di DKI Jakarta dan sekitarnya. Jakarta: Pusat Penelitian Unika Atmajaya; 1995. 